\title{
Uma questão de estilo: Estudo dos obituários da Folha
} de S. Paulo

A matter of style: the production of two obituary writers of the newspaper Folha de S. Paulo

\section{Monica Martinez}

Doutora em Ciências da Comunicação, pela Escola de Comunicações e Artes da Universidade de São Paulo - ECA/USP, com pósdoutoramento em Narrativas Digitais, pela Universidade Metodista de São Paulo - Umesp; professora do Programa de Mestrado em Comunicação e Cultura da Universidade de Sorocaba - Uniso

\begin{abstract}
Resumo
Para avaliar a hipótese de que o estilo e/ou voz autoral seriam características de uma narrativa em jornalismo literário, esta pesquisa tem como objeto a seção "Mortes", do jornal Folha de S. Paulo, implementada em 30 de outubro de 2007. O corpus do estudo concentra-se nos obituários publicados no ano de 2008. Os resultados sugerem que, mesmo no contexto de uma publicação conhecida por seguir um manual de redação desde 1984, o estilo único e, consequentemente, a voz autoral do jornalista podem ser observados.
\end{abstract}

Palavras-Chave: Folha de S. Paulo; obituários; estilo.

\begin{abstract}
To evaluate the hypothesis that the style and /or authorial voice would be characteristic of a narrative in Literary Journalism, this research investigates the Deaths section of the newspaper Folha de S. Paulo, which was implemented on October 30, 2007. The corpus of the study focuses on the obituaries published in 2008. The results suggest that, even in the context of a publication known to follow a newsroom manual since 1984, the unique style and therefore the authorial voice of the journalist can be observed in both cases.
\end{abstract}

Keywords: Folha de S. Paulo; obituaries; style. 


\section{Uma questão de estilo: Estudo dos obituários da Folha de S. Paulo}

\section{Reflexões sobre estilo e a escrita}

A rigor, estilo é a forma pessoal de alguém fazer alguma coisa. Os verbetes de dicionários, em geral simples de compreender, podem não ser esclarecedores neste caso. É que estilo é algo bastante complexo de se definir. A análise do estilo de gerenciar de fulano, por exemplo, envolve um vasto número de elementos. Sicrano pode ter um estilo de comportamento relaxado ou tenso. Da mesma forma, estilo não é algo estático, mas evolui ao longo do tempo, como as pinturas do espanhol Pablo Picasso (1881-1973). E, como no cenário efêmero da moda, o simples fato de a pessoa combinar vestimentas e acessórios da estação não necessariamente garante que ela seja bem-sucedida no desafio de criar um estilo diferenciado e pessoal.

E o que seria estilo literário? Para Domício Proença Filho, professor aposentado da Universidade Federal Fluminense, há duas esferas da língua. A primeira, que envolve a dimensão sócio-histórica, caracteriza-se por ser sistemática, sendo denominada de estilo de época uma vez que as manifestações artísticas compartilhariam tendências com a "religião, psicologia, sociologia, nas formas de polidez, nos costumes, vestuários, gestos etc." (PROENÇA FILHO, 2007: 26).

Já a segunda dimensão refere-se à utilização individual que cada um faz do idioma, caracterizando-se, portanto, como fala ou discurso. "Ao assumir o discurso, cada indivíduo busca escolher os meios de expressão que melhor configurem suas ideias, pensamentos e desejos. Essa escolha é que caracteriza o estilo" (PROENÇA FILHO, 2007: 26). Ainda segundo o estudioso:

Explicitando um pouco mais, podemos entender o estilo, em sua dimensão individual, e a partir do conceito de Helmut Hatzfeld, como o aspecto particular que caracteriza a utilização individual da língua e que se revela no conjunto de traços situados na escolha do vocabulário, na ênfase nos termos concretos ou abstratos, na preferência por formas verbais ou nominais, na propensão para determinadas figuras de linguagem, tudo isso estreitamente veiculado à organização do que se diz ou escreve e a um intento de expressividade (idem).

A questão situa-se, portanto, na esfera do autor, que foi objeto de muitos estudos literários nas últimas décadas. Segundo o semioticista francês Roland Barthes (19151980):

(...) nas sociedades etnográficas não há nunca uma pessoa encarregada da narrativa, mas um mediador, châmane ou recitador, de que podemos em rigor admirar a prestação (quer dizer, o domínio do código narrativo), mas nunca o "gênio". O autor é uma personagem moderna, produzida sem dúvida pela nossa sociedade, na medida em que, ao terminar a Idade Média, com o empirismo inglês, o racionalismo francês e a fé pessoal da Reforma, ela descobriu o prestigio pessoal do indivíduo, ou como se diz mais nobremente, da "pessoa humana". É, pois, lógico que, em matéria de literatura, tenha sido o positivismo, resumo e desfecho da ideologia capitalista, a conceder a maior importância à "pessoa" do autor (BARTHES, 1984: 49).

Ao conceito de autor, Barthes contrapôs o de scriptor:

O Autor, quando se acredita nele, é sempre concebido como o passado do seu próprio livro: o livro e o autor colocam-se a si próprios numa mesma linha, distribuída como um antes e um depois: supõe-se que o Autor alimenta o livro, quer dizer que existe antes dele, pensa, sofre, vive com ele; tem com ele a mesma relação de antecedência que um pai mantém com o seu filho. Exatamente ao contrário, o scriptor moderno nasce ao mesmo tempo em que ( $\mathrm{sic}$ ) o seu texto; não está de modo algum provido de um ser que precederia ou excederia a sua escrita, não é de modo algum o sujeito de que o seu livro seria o predicado; não existe outro tempo para além do da enunciação, e todo o texto é escrito eternamente aqui e agora (BARTHES, 1984: 51).

Barthes retirou também do autor a ideia de uma suposta originalidade individual, propondo o texto como uma obra coletiva, neste sentido antecipando-se ao conceito de mente-colmeia, associado às construções coletivas surgidas após o advento da internet, como a Wikipédia:

Sabemos agora que um texto não é feito de uma linha de palavras, libertando um sentido único, de certo modo teológico (que seria a "mensagem" do Autor-Deus), mas um espaço de dimensões múltiplas, onde se casam e se contestam escritas variadas, nenhuma das quais é original: o texto é um tecido de citações, saldos dos mil focos da cultura (BARTHES, 1984: 51-52).

Outro pensador que discutiu a relação entre estilo e autoria foi o russo Mikhail Bakhtin (1895-1975), estudioso de teoria literária, que propôs questões como: "Qual a relação do estilo e o autor em sua individualidade? Qual é a relação do estilo com o conteúdo, ou seja, com o mundo dos outros, objeto de acabamento? Qual é o significado da tradição no contexto de valores do autor-contemplador?" (BAKHTIN, 2000: 215). Neste contexto, Bakhtin entendeu estilo como a unidade constituída pelos procedimentos empregados para dar forma e acabamento ao texto, criticando a rigidez, uma vez que compreendeu estilo não como algo estático, porém como um processo.

Apesar de defender a morte do autor, o próprio Barthes era ciente de a cultura ser "tiranicamente centrada no autor, na sua pessoa, na sua história, nos seus gostos, nas suas paixões" (BARTHES, 1984: 50). Note-se que ele faleceu antes do advento da internet e antes que outros filósofos, como o também francês Giles Lipovetsky, postulassem que, se a era do individualismo não é invenção recente, ela continua em curso, "colocando o indivíduo livre e igual como valor central de nossa cultura, como fundamento da ordem social e política" (LIPOVETSKY \& SERROY, 2011: 47). 
De toda forma, se a teoria literária é pródiga em estudos sobre a autoria, a prática não fica atrás. O mercado editorial tradicionalmente encoraja que o autor manifeste seu estilo, uma vez que se trata de uma importante marca de identidade, que favorece a vinculação do público com este ou aquele tipo de obra. Além disto, a própria crítica tende a contextualizar a obra a partir da visão do autor, isto é, de quem a produziu.

\section{A fronteira tênue entre a literatura e o jornalismo}

À semelhança dos estudos literários, há reflexões sobre estilo em jornalismo. Contudo, e embora estas duas áreas do conhecimento compartilhem a mesma matériaprima - a escrita -, elas possuem visões diferenciadas sobre a questão. Há estudiosos que apontam a dificuldade em estabelecer uma linha clara entre elas. "Se existe uma fronteira entre a narrativa literária e a jornalística, ela não é facilmente demarcável" (OLIVEIRA, 1991: 29). $\mathrm{E}$ há pesquisadores, como Nilson Lage, da Universidade Federal de Santa Catarina, que defendem que o jornalismo não é um gênero literário (1999: 35).

Outros especialistas da matéria, como Cristiane Costa, do curso de Jornalismo da Escola de Comunicação da Universidade Federal do Rio de Janeiro (ECO/UFRJ), entendem que este debate é coisa do passado:

Hoje, a velha questão se jornalismo é ou não um gênero literário, levada a cabo por Alceu Amoroso Lima, tornouse obsoleta. A dúvida sobre se o jornalismo merece ou não ser enquadrado como subgênero literário revelou-se uma consequência do processo histórico que permitiu a elevação da ficção a uma categoria quase transcendente no século XIX, graças ao rebaixamento do jornalismo ao puramente factual e comercial (COSTA, 2005: 306).

Contudo, outros estudos sugerem que esta relação entre autor e obra ainda se trata de uma questão não conclusiva em jornalismo. Ainda que o assunto "estilo" esteja longe de ser novo em jornalismo, de fato, ele é discutido há pelo menos quatro séculos no Ocidente, uma vez que pode ser identificado na primeira tese de doutorado escrita sobre jornalismo, apresentada em 1690 pelo pesquisador alemão Tobias Perceur à Universidade de Leipzig, na Alemanha:

$\S$ XXII. A expressão (léxis) ou modo de dizer, ou estilo dos periódicos, não há de ser nem oratório nem poético. Porque aquele distancia o leitor desejoso de novidade; e este lhe causa confusão além de não expor as coisas com clareza suficiente. Em compensação, o narrador, se quer agradar, precisa seguir antes o fato como ele sucedeu. Veja Cícero, livro II, De oratore. Pois bem, para este fim o narrador se faz servir uma linguagem por um lado pura, mas por outro, clara e concisa. Isto é asseverado por Cícero no seu Brutus: "Não há nada, disse, que seja tão

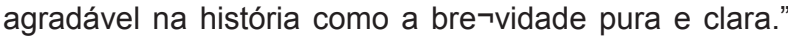
Por isso cabe evitar as palavras obscuras e a confusão na ordem sintática (PERCER, 2000: 213).

Nos Estados Unidos, as diretrizes sobre estilo remontam a 1886, quando Robert Luce (1862-1946) lançou o Manual for editors, reporters, correspondents, and printers, tido como o primeiro manual moderno de jornalismo (LUCE,
2008; SALAVERRÍA apud CAPRINO, 2002: 100). Na epígrafe do livro, o crítico literário mais famoso da época, Richard Grant White (1822-1855), já dizia que "uma escrita imprecisa é geralmente a expressão de um pensamento ao qual falta clareza" (LUCE, 2008), provavelmente dando a recomendação mais eficaz sobre escrita.

No Brasil, o primeiro manual de redação foi implantado pelo sociólogo pernambucano Gilberto Freyre no final da década de 1920, quando, ao retornar dos Estados Unidos, foi diretor do jornal A Província (MARQUES DE MELO, 2005: 201). Contudo, a implantação seria acentuada após a Segunda Guerra Mundial, época em que, inspirados no modelo estadunidense, os manuais seriam implantados gradualmente nas redações jornalísticas numa tentativa de padronizar a linguagem da publicação:

A reforma do estilo da imprensa brasileira começou na década de 1950, em um pequeno jornal do Rio de Janeiro, o Diário Carioca (que circulou entre 1928 e 1966), onde foram introduzidos pelos jornalistas Danton Jobim e Pompeu de Souza três importantes elementos oriundos do jornalismo norte-americano: o lead, o manual de redação e o copy desk (redator responsável por reescrever as matérias, dando um tratamento uniforme a todos os textos). Esse novo padrão textual não se espalhou de imediato por toda a imprensa. O que aconteceu foi a convivência entre elementos do moderno estilo jornalístico com vícios da forma de escrever dominante até então (CAPRINO, 2002: 99-100).

Em estudo comparativo sobre cinco manuais de redação para seu trabalho de conclusão pela Universidade Federal de Santa Maria, a jornalista Jacira Werle Rodrigues investigou a questão de estilo e concluiu que:

Cada manual de redação, entre os cinco analisados, aborda as orientações de estilo de uma forma e em quantidade diferentes. A Folha traz a recomendação de que cada palavra do texto deve servir para passar a informação da melhor maneira possível. O Estado é o mais detalhista, além de apresentar uma consistente parte sobre gramática. O manual do jornal $O$ Globo é o que faz mais demonstrações de incentivo ao desenvolvimento estilístico do jornalista. Zero Hora caracteriza o estilo com dois substantivos - elegância e precisão -, além de ressaltar a necessidade de serem produzidas publicações de qualidade para o leitor, sem clichês, linguagem chula ou textos grandes e enfadonhos. A Abril, cujo manual se intitula de estilo, faz poucas recomendações, motivados, acredita-se, em duas particularidades da empresa: ela trabalha com revistas e as publicações são de assuntos variados. Dessa forma, o manual inclui poucas e diretas dicas sobre como resolver um problema como, por exemplo, de que forma colocar uma citação no meio do texto (RODRIGUES, 2003: 90).

Os manuais, portanto, se calam ou apontam poucos caminhos sobre estilo, refletindo, de certa forma, a mentalidade hegemônica das redações contemporâneas de que não seria possível a coexistência de estilo e de padronização textual numa mesma publicação. Essa batalha, aliás, foi registrada de forma espirituosa por Mario Vargas Llosa em Tia Julia e o escrevinhador, romance autobiográfico escrito nos anos 1970 pelo escritor peruano, no qual ele descreveu um embate 
textual travado entre Pascual, o encarregado de redigir os boletins noticiosos, e o protagonista, então diretor de informações da Rádio Panamericana:

Em minha edícula da Panamericana, encontrei Pascual com o boletim das nove já pronto. Começava com uma dessas notícias de que tanto gostava. Ele a tinha copiado de La Crónica, enriquecendo-a com adjetivos de seu próprio acervo: "No proceloso mar das Antilhas, naufragou ontem à noite o cargueiro panamenho Shark, tendo perecido oito ocupantes, afogados e mastigados pelos tubarões que infestam o citado mar". Troquei "mastigados" por "devorados" e eliminei o "proceloso" e "citado" antes de dar o visto final. Ele não se zangou, porque Pascual não se zangava nunca, mas deixou lavrado seu protesto: - Esse don Mario, sempre fodendo com meu estilo (LLOSA, 2012: 50).

\section{Jornalismo literário e estilo}

Se não é uma palavra-chave em jornalismo convencional, estilo é decididamente relevante em jornalismo literário. Como conceito, no contexto deste artigo, entende-se jornalismo literário como: "Modalidade de prática da reportagem de profundidade e do ensaio jornalístico, utilizando recursos de observação e redação originários da (ou inspirados pela) literatura" (LIMA, 2000), proposto pelo ex-docente da Universidade de São Paulo, Edvaldo Pereira Lima, hoje vice-presidente da ABJL (Associação Brasileira de Jornalismo Literário).

John Hartsock, professor do departamento de Communication Studies da Suny em Cortland, um dos 64 campi da Universidade Estadual de Nova lorque, lembrou que "jornalismo literário não é de maneira alguma a designação universal para esta forma" (HARTSOCK, 2000: 3) $)^{1}$ :

Eu prefiro "jornalismo narrativo" como um termo descritivo simples, ou "jornalismo narrativo literário" uma vez que tais obras são fundamentalmente narrativas em vez de discursivas. Dado que o primeiro termo não tem o aval da crítica corrente, e dado que o empilhamento de adjetivos no segundo é considerado estilo ruim, eu decidi ficar com "jornalismo literário" com o entendimento de que os textos sob consideração estão no modo narrativo. Futuras discussões entre os estudiosos terão que culturalmente construir qualquer nomenclatura definitiva, se tal nomenclatura for possível (HARTSOCK, 2000: 3).

Quanto ao estilo em jornalismoliterário, em 1995, o docente e jornalista estadunidense Mark Kramer já o apontava como um dos traços básicos da modalidade: "Estilo conta e tende a ser simples e econômico" (KRAMER, 1995 $30)^{2}$. Sobre a questão, Hartsock disse que:

Barbara Lounsberry identifica quatro características definidoras desta forma, três das quais derivam de Wolfe e Sims. (...) A quarta - e sua contribuição original à taxonomia - é talvez a mais problemática para uma posição pós-moderna. Lounsberry sugere que uma obra de jornalismo literário deve ser infundida com o que Annie Dillard chama de "boa escrita" e Gay Talese caracteriza como "escrever com estilo". (...) Porque estas tentativas de teorizar a forma tratam do que eu distingo como características retóricas e intencionais "externas", tanto naturalmente está aberto ao debate, não sendo o menor item o que se constitui como "boa escrita" (HARTSOCK, 2000: 256) ${ }^{3}$.

Lima combinou ao estilo a voz autoral, aspectos que, para ele, têm a ver com "ver o mundo com olhar diferenciado, liberto de condições limitadoras que empobrecem a visão (...). Pois a singularidade do olhar do autor transmite à obra um toque de exclusividade que a diferencia, valorizando-a" (LIMA, 2009: 369):

A voz autoral significa que o leitor aceita a diversidade que marca as diferenças entre os diversos autores. Jornalismo Literário não é um modo narrativo de textos iguais. (...) Essa diversidade é o que o torna interessante, para o leitor. Espera-se que o autor assuma sua postura própria, individual, que tenha a marca pessoal diante da realidade, sua assinatura diante da vida. Espera-se que essa voz autoral traduza-se num estilo próprio, um modo também único de combinar os elementos da narrativa (LIMA, 2009: 371).

Já Alexander Steele, reitor da Gotham Writers, escola de escrita criativa de Nova lorque, traçou uma didática separação conceitual entre estilo e voz ${ }^{4}$.

1 Do original: "Literary Journalism' is by no means the universal designation for the form. (...) I prefer 'narrative journalism' as a simple descriptive term, or 'narrative literary journalism' since such works are fundamentally narrative rather than discursive. Given the first has no critical current cachet, and given than the piling on of adjectives in the second is considered bad style, I have decided to stay with 'literary journalism' with the understanding that the texts under consideration are narrative in mode. Future discussions among scholars will have to culturally construct any final nomenclature, if such a nomenclature is possible." Esta e as demais traduções livres que se seguem foram feitas pela autora.

2 Do original: "Style counts and tends to be plain and spare".

3 Barbara Lounsberry identifies four defining characteristics of the form, three of which are derived from Wolfe and Sims. (...) The fourth - and her original contribution to taxonomy is perhaps the most problematic to a postmodern position. Lounsberry suggests that a work of literary journalism should be infused with what Annie Dillard calls "fine writing" and Gay Talese characterizes as "writing with style". (...) Because these attempts to theorize the form address what I characterize as "external" rhetorical and intentional characteristics, much of course is open to debate, not the least of which is what constitutes "fine writing" (HARTSOCK, 2000: 256).

4 People often use the terms voice and style interchangeably, but there's an enormous difference from the writer's perspective. Style consists of various technical choices made by a writer, and the voice is the sum result of those choices. If voice is the velvet dress, style is the fabrics, threads, buttons, and such that create the garment. The dirty truth is that a piece's voice is created by the most elemental tools in writing - namely, what words you pick, how you string them together in a sentence, and how you mix and match your sentences to form paragraphs. Hemingway used short sentences. Short sentences and repetition. Dorothy Parker liked to throw around the slang, know what I mean. Nabokov favored amplitudinous words. Though these things may seem very technical, you'll see just how closely stylistic choices relate to the personality of the narrator and the story's content (STEELE, 2003: 182). 
As pessoas frequentemente usam os termos voz e estilo como sinônimos, mas há uma diferença enorme a partir da perspectiva do escritor. O estilo consiste de várias escolhas técnicas feitas pelo escritor e a voz é a soma resultante dessas escolhas. Se a voz é o vestido de veludo, o estilo consiste nos tecidos, fios, botões e tais que criam a vestimenta. A verdade é que a voz de uma peça é criada pelas ferramentas mais elementares de escrita - a saber, as palavras que você escolhe, como você as agrega em uma frase e como você mistura e combina as suas frases para formar os parágrafos. Hemingway usava frases curtas. Frases curtas e repetição. Dorothy Parker gostava de jogar em torno da gíria, sabe o que eu quero dizer. Nabokov favorecia palavras amplas. Embora essas coisas possam parecer muito técnicas, você vai ver o quão estreitamente escolhas estilísticas se relacionam com a personalidade do narrador e o conteúdo da história (STEELE, 2003: 182).

Assim, ao evocar o estilo de Tom Wolfe, o grande pensador do movimento do Novo Jornalismo, a professora de Jornalismo na Universidade de Minesota, Kathy Roberts Forde, lembrou que seu estilo assim se caracterizava 5 :

As histórias de Wolfe examinam em um estilo de prosa surpreendente fresco as subculturas e contraculturas que estavam aparecendo em toda a América na década de sessenta. Seu estilo característico inclui epítetos repetidos, imitação fonética da fala e sons e as mudanças rápidas no ponto de vista, um estilo sugerido no ensaio que dá título ao livro: "There Goes (Varoom Varoom!!) Que Kandy-Kolored (Thphhhhhh!) Tangerine -Flake Streamline baby (Rahghhh!) Around the Bend (Brummmmmmmmmmmmmmm) (FORDE, 2008: 52).

O estilo seria menos notado na esfera dos textos noticiosos, isto é, relativos às coberturas diárias, em geral feitas de forma veloz devido à necessidade de reportálas com atualidade aos leitores. No entanto, a hipótese é a de que seria mais evidente nas reportagens especiais e, sobretudo, nas narrativas biográficas, uma vez que o jornalista teria menos pressão de tempo e, assim, mais liberdade para empreender uma escrita aprofundada e criativa.

\section{Procedimentos metodológicos}

A partir deste raciocínio, o objeto de estudo desta pesquisa foi o jornal paulista Folha de S. Paulo, o primeiro em circulação nacional no período de 1986-2010, quando, segundo dados do Instituto Verificador de Circulação (IVC), o jornal perdeu a liderança para o diário popular Super Notícia, de Belo Horizonte (Minas Gerais). A escolha do objeto deve-se ao fato de que, desde 2007, o jornal publica a coluna "Mortes", que diariamente traz um obituário que o jornalista responsável produz a partir de apuração jornalística e redação aprofundada, uma vez que há uma média de sete dias entre o falecimento e a publicação da notícia (MARTINEZ, 2012).

Para se avaliar se há evidências de estilo autoral nestes relatos biográficos curtos, o corpus do estudo refere-se às colunas publicadas no ano de 2008, que marcou a transição do primeiro jornalista responsável pelos obituários, William
Vieira (30 de outubro de 2007 a 18 de agosto de 2008), ao segundo e atual obituarista, Estevão Bertoni (19 de agosto de 2008 aos dias atuais). A seleção de textos foi aleatória, coletando-se o do primeiro dia de cada mês. O resultado foi um total de oito textos de Vieira (janeiro a agosto) e quatro de Bertoni (setembro a dezembro). De modo a reduzir para o mesmo número o corpus colhido de cada jornalista, novamente de forma aleatória, foram selecionados os textos de Vieira publicados nos primeiros dias dos meses pares (fevereiro, abril, junho e agosto).

Resolvidas as questões sobre o que analisar e onde analisar, foram estabelecidas as categorias de análise a partir das referências básicas de estilo, a saber: a escolha das palavras, a construção das sentenças e como elas são agregadas em parágrafos. A partir desta base, foi empreendida uma segunda análise para tentar compreender a voz autoral.

\section{Resultados da pesquisa}

Ao se analisar a base da escritura dos dois obituaristas da Folha de S. Paulo, percebe-se que, em comum, ambos empregam um vocabulário simples, porém eficaz, para relatar as notícias de falecimento. Não há palavras obscuras, que, para serem decifradas, demandariam uma consulta ao dicionário. Ainda assim, o texto flui de forma agradável, sendo simples, porém nunca simplório.

Notam-se, contudo, diferenças na construção das sentenças. Vieira tendia a escrever sentenças em ordem direta, enxutas, que, por isso, resultam mais claras e fluentes. "Pivete era um menino negro e pobre que não se dava por vencido, cheio de artimanhas para driblar a vida de rua." Estas sentenças foram redigidas de forma criativa, chegando a romper o paradigma que sugere a não repetição de palavras ("Gaúcho daqueles gaúchos mais gaúchos de Caxias do Sul..."), devido à intenção de imprimir ritmo à narrativa.

Já o estilo de Bertoni é menos sintético e econômico. O jornalista emprega palavras em profusão para construir sentenças fornidas que, por conta dos excessos, resultam menos diretas, porém carnudas e saborosas. ("Outro vestígio que fortalece a suspeita foi a bandeira do São Paulo que estava sobre seu caixão"). Neste caso, se a ideia fosse produzir uma frase enxuta, a sentença poderia simplesmente ser "Outra evidência foi a bandeira do São Paulo sobre seu caixão", por exemplo.

Bertoni também emprega recursos não habituais no texto de jornais, como o uso do vocativo para atrair a atenção

5 Wolfe's stories examined in a startling fresh prose style the subcultures and countercultures popping up across America in the sixties. His characteristic style included repeated epithets, phonetic imitation of speech and sounds, and rapid shifts in viewpoint, a style hinted at in the title essay of the book: "There Goes (Varoom! Varoom!) That Kandy-Kolored (Thphhhhhh!) Tangerine - Flake Streamline Baby (Rahghhh!) around the Bend (Brummmmmmmmmmmmmm) (FORDE, 2008: 52). 
Quadro 1 - Comparação entre os estilos de Bertoni e Vieira

\begin{tabular}{|c|c|c|c|}
\hline & Palavras & Sentenças & PARÁGRAFos \\
\hline $\begin{array}{l}\text { Estevão } \\
\text { Bertoni }\end{array}$ & $\begin{array}{l}\text { Vocabulário } \\
\text { simples } \\
\text { e bem } \\
\text { escolhido }\end{array}$ & $\begin{array}{c}\text { Uso de recursos } \\
\text { raros em diários, } \\
\text { como o vocativo. } \\
\text { As frases são } \\
\text { encorpadas, } \\
\text { com profusão de } \\
\text { palavras. }\end{array}$ & $\begin{array}{l}\text { Segue o padrão } \\
\text { Folha, no qual } \\
\text { as sentenças } \\
\text { curtas são } \\
\text { articuladas em } \\
\text { parágrafos que } \\
\text { não excedem } \\
\text { seis linhas. }\end{array}$ \\
\hline $\begin{array}{l}\text { William } \\
\text { Vieira }\end{array}$ & $\begin{array}{l}\text { Vocabulário } \\
\text { simples } \\
\text { e bem } \\
\text { escolhido }\end{array}$ & $\begin{array}{c}\text { Redação criativa } \\
\text { As frases são } \\
\text { secas, enxutas, } \\
\text { econômicas. }\end{array}$ & $\begin{array}{l}\text { Os parágrafos } \\
\text { são maiores, } \\
\text { chegando a oito } \\
\text { linhas. }\end{array}$ \\
\hline
\end{tabular}

do leitor. No obituário de Adelina Clara Hess de Souza, o leitor ainda não sabe que se trata da idealizadora da maior camisaria brasileira, a Dudalina. O jornalista antecipou a questão de forma interessante: "Aos 19, Adelina conheceu Rodolfo Francisco de Souza Filho, cujo apelido era Duda. Atenção para os nomes: Duda e Adelina. No final da década de 1950, o inquieto espírito empreendedor de Adelina levou à fundação de uma camisaria. O nome? Dudalina".

A combinação das sentenças em parágrafos também demonstra estratégias textuais diferentes. No caso de Vieira, como as frases são mais concisas, os parágrafos são maiores sem que haja prejuízo para a compreensão. É o caso de um dos maiores parágrafos da amostra:

Hidekazu Masuda pesquisava, traduzia e escrevia os poemas de poucas palavras. Sabia o peso da "missão" a ele confiada por Nempuku Sato, pioneiro do haicai no Brasil e que Ihe introduzira à arte. Foi em 1936 que leu os primeiros poemas e passou a fazê-los, em japonês e português. Assim o homem de Kagawa, Japão, que chegou ao Brasil em 1929 e por anos trabalhou na lavoura do café e por outros na quitanda do pai em Pedregulho $(\mathrm{SP})$, chegou a São Paulo como poeta.

Já em "Caldeirão espanhol, português e italiano", a abertura do obituário de Iracy Gaze Duran revela-se um pouco confusa:

Para aquelas três famílias, todos os caminhos levaram à Vila Mariana, na zona sul de São Paulo. Os Gazze, italianos, desviaram-se de Roma e acabaram desembarcando em terras brasileiras. Os Duran e os Rodrigues, espanhóis e portugueses, respectivamente, redescobriram a América. E misturaram-se todos numa família só, no bairro paulistano.

A explicação, subentendida, chega apenas no segundo parágrafo: "Para a menina Iracy Gaze Duran, filha de imigrantes portugueses e italianos, não foi diferente".

\subsection{Construções simbólicas da realidade}

No âmbito da voz autoral, seria possível estabelecer várias considerações sobre os autores a partir dos textos analisados. No entanto, a principal relação observada nesta pesquisa refere-se à estrutura narrativa. Os textos de Estevão Bertoni são bastante concretos, no sentido de que buscam narrar a história de uma forma resumida, destacando alguma particularidade pessoal do(a) falecido(a). "Foram viver juntos. Atualmente, estavam em processo de adoção de uma menina de sete anos, que o casal criou desde que a garota nasceu - seu sonho era tê-la oficialmente como filha."

Já a preocupação de William Vieira parece ter sido diferente, no sentido de apurar detalhes significativos da vida do(a) morto(a) ou a ela associados, de forma a construir a história de vida a partir deste conjunto. "Quanta briga não houve entre crianças do Brasil inteiro por aquele conjuntinho de prato, copo e talher de aço riscado com carinhas infantis - fetiche de infância de uma geração no sul do país?" A partir desta introdução, que parece ter sido escrita com base em uma lembrança do próprio jornalista, Vieira narrou o falecimento do designer gaúcho: "Na casa de José Carlos Bornancini, o pai da criação, os dois filhos tinham os seus intocáveis, lá nos anos 1970. Mas os cinco netos não tiveram sorte igual. Os dois conjuntos que sobraram 'eram disputados a tapa'".

No âmbito das funções da linguagem (CHALHUB, 2006), em particular dos estudos do linguista russo Roman Jakobson (1896-1982), Bertoni estaria usando com mais frequência a função referencial (transmissão de informações objetivas), algumas vezes também a conativa (visando à sedução do leitor). Já Vieira estaria no escopo da emotiva, imprimindo no texto seus sentimentos, o que o fazia alcançar, algumas vezes, a poética (quando a mensagem é inovadora e surpreendente por sua própria configuração).

\section{Considerações finais}

Esta pesquisa comparativa entre os textos dos dois obituaristas da Folha de S. Paulo, William Vieira (responsável pela coluna "Mortes" no período de 30 de outubro de 2007 a 18 de agosto de 2008) e Estevão Bertoni (de 19 de agosto de 2008 até a presente data), sugere que é possível notar o estilo de escrita de cada autor, ainda que a coluna se insira num jornal que tenha um manual de redação há quase três décadas e que, certamente, cobre padronização de seus colaboradores.

Nota-se que o estilo do primeiro obituarista, William Vieira, é mais enxuto, que suas construções frasais são sintéticas, o que permite a construção de parágrafos maiores sem prejuízo para a fluência da narrativa. Já sua voz autoral privilegia contar as histórias de forma a ressaltar detalhes significativos da vida do(a) falecido(a), usando para isto funções da linguagem emotiva e poética.

O estilo do segundo obituarista, Estevão Bertoni, é bem diferente. Suas frases, consistentes e carnudas, fazem os parágrafos - ainda que menores em relação ao primeiro obituarista - parecerem mais encorpados. A voz autoral se faz revelar, talvez de forma inconsciente, na escolha dos personagens, uma vez que, no corpus da pesquisa, dois dos quatro textos analisados de Bertoni referem-se a homens torcedores de futebol (um do São Paulo e outro 
do Palmeiras). Quanto às funções da linguagem, os textos estariam mais próximos da referencial e da conativa, numa intenção de transmitir corretamente a informação e convidar o leitor eventualmente a seguir na leitura.

Infelizmente - ou talvez felizmente -, nem todos os elementos de estilo são mensuráveis ou apreensíveis. Como disse o professor de Inglês Chris Anderson, da Oregon State University6:

O estilo é uma espécie de mágica. Ele transcende a simples comunicação, a transmissão de informações e de fatos. Ele existe como uma espécie de aura entre as linhas, no espaço em branco em torno do texto. O estilo se desenvolve a partir de que não é dito e do que não pode ser dito. Talvez a partir dessa perspectiva, o que parece uma simples "cerimônia de estilo", um conjunto de estratégias abertas para a esfera da estética, realmente desenvolve uma força filosófica e temática próprias. Estilo torna-se um argumento para o estilo, pois não pode ser medido, explicado, reduzido ao explícito (ANDERSON, 1987: 76).

É isto o que, provavelmente, faz a leitura dos obituários em geral, e desta coluna da Folha de S. Paulo em particular, ser interessante, independentemente do autor ou das histórias que estão sendo contadas. $O$ fato de cada texto - em seu processo de apuração e redação - ser único. Como a vida que, para as pessoas ali referenciadas, serviu de base.

6 Style is a kind of magic. It transcends simple communication, the transaction of information and fact. It exists as a kind of aura between the lines, in the blank space surrounding the text. Style develops from what is not said and what cannot be said. Perhaps from this perspective, what seems a mere "ceremony of style", a set of strategies open to the charge of aestheticism, really develops a philosophical and thematic force of its own. Style becomes an argument for style, for that which cannot be measured, explained, reduced to the explicit (ANDERSON, 1987: 76). 


\section{Referências}

BABROW, Austin S. \& MATTSON, Marifran. Theorizing ANDERSON, Cris. Style as argument: contemporary American nonfiction. Carbondale: Southern Illinois University Press, 1987.

BAKHTIN, Mikahil. Estética da criação verbal. São Paulo: Martins Fontes, 2000.

BARTHES, Roland. A morte do autor. In: BARTHES Roland. O rumor da língua. Lisboa: Ed. 70, 1984.

CAPRINO, Mônica Pegurer. Questão de estilo: o texto jornalístico e os manuais de redação. Comunicação \& Sociedade, v. 23, n. 37, p. 95-113, São Bernardo do Campo, 1o semestre, 2002.

CHALHUB, Samira. Funções da linguagem. São Paulo: Ática, 2006.

COSTA, Cristiane. Pena de aluguel: escritores jornalistas no Brasil 1904-2004. São Paulo: Companhia das Letras 2005.

FORDE, Kathy Roberts. Literary journalism on trial: Masson v. New Yorker and the First Amendment. Boston: University of Massachusetts Press, 2008.

HARTSOCK, John C. A history of American literary journalism: the emergence of a modern narrative form. Boston: University of Massachusetts Press, 2000.

KRAMER, Mark. Breakable rules for literary journalists. In: SIMS, Norman \& KRAMER, Mark. Literary journalism: a new collection of the best American nonfiction. New York: Ballantine Books, 1995. p. 21-34.

KRAMER, Mark \& CALL, Wendy. Telling true stories: a nonfiction writers'guide from the Nieman Foundation at Harvard University. New York: Plume, 2007.

LAGE, Nilson. Linguagem jornalística. 2. ed. São Paulo: Ática, 1999

LIMA, Edvaldo Pereira. Conceitos. Academia Brasileira de Jornalismo Literário, São Paulo, s/d. Disponível em: <http://
www.abjl.org.br/index.php?conteudo=Conceitos\&lang=> Acesso em: 10 de outubro de 2000.

Páginas ampliadas: o livro-reportagem como extensão do jornalismo e da literatura. 4. ed. Barueri: Manole, 2009.

LIPOVETSKY, Gilles \& SERROY, Jean. A cultura-mundo - resposta a uma sociedade desorientada. São Paulo: Companhia das Letras, 2011.

LLOSA, Mario Vargas. Tia Julia e o escrevinhador. São Paulo: Mediafashion, 2012.

LUCE, Robert. Writing for the press: a manual for editors, reporters, correspondents, and printers. Charleston: BiblioBazaar, 2008.

MARTINEZ, Monica. Jornada do herói: estrutura narrativa mítica na construção de histórias em jornalismo. São Paulo: Annablume/Fapesp, 2008.

A vida em 20 linhas: obituários e jornalismo literário. In: XXXV CONGRESSO BRASILEIRO DE CIÊNCIAS DA COMUNICAÇÃO. Anais... Fortaleza: Intercom/Unifor, 2012.

MARQUES DE MELO, José (Org.). Imprensa brasileira: personagens que fizeram história. São Paulo: Umesp/ Imprensa Oficial, 2005.

OLIVEIRA, Oswaldo Coimbra de. Elementos da estrutura do texto da reportagem. 1991. 324p. Tese (Doutorado em Comunicação) - Escola de Comunicações e Artes da Universidade de São Paulo. São Paulo: ECA/USP.

PEUCER, Tobias. Os relatos jornalísticos. Comunicação \& Sociedade, v. 22, n. 33, p. 199-214, São Bernardo do Campo, 10 semestre, 2000.

PROENÇA FILHO, Domício. A linguagem literária. São Paulo: Ática, 2007.

RODRIGUES, Jacira Werle. Reportagem impressa, estilo e manuais de redação: a construção da autoria nos textos do jornalismo diário. Santa Maria: Facos/ UFSM, 2003. 